\title{
ANA MARÍA LORANDI Y LA SECCIÓN ETNOHISTORIA DEL INSTITUTO DE CIENCIAS ANTROPOLÓGICAS, UNIVERSIDAD DE BUENOS AIRES
}

\author{
ANA MARÍA LORANDI AND THE SECTION ETHNOHISTORY OF THE INSTITUTE \\ OF ANTHROPOLOGICAL SCIENCES, UNIVERSIDAD DE BUENOS AIRES
}

\author{
Carlos E. Zanolli*
}

\begin{abstract}
El presente trabajo rescata la obra de Ana María Lorandi como directora de la Sección Etnohistoria del Instituto de Ciencias Antropológicas, Facultad de Filosofía y Letras de la Universidad de Buenos Aires. Se detendrá en cómo Lorandi ha ido ampliando la cantidad de tesistas e investigadores a partir de la obtención de subsidios y cómo el incremento del personal ha favorecido, a su vez, el de temas de investigación.
\end{abstract}

Palabras clave: Ana María Lorandi, Sección Etnohistoria, investigación.

The present work rescues the work of Ana María Lorandi as Director of the Ethnohistory Section of the Institute of Anthropological Sciences, Faculty of Philosophy and Letters of the University of Buenos Aires. It will stop at how Lorandi has been increasing the number of tesists and researchers from the obtaining of subsidies and as the increase of the personnel has favored, in turn, the one of subjects of investigation.

Key words: Ana María Lorandi, Ethnohistory Section, research.

\section{Introducción}

Al momento de su fallecimiento, Ana María fue recordada por sus colegas por diversos motivos: destacaron su generosidad para con ellos, sus estudios pertinentes al Tucumán colonial, que haya realizado el primer Congreso Internacional de Etnohistoria, sus trabajos acerca de la frontera sur del imperio incaico, etc. En este trabajo me voy a detener en un aspecto de la obra de Ana María sin la cual tal vez ella no hubiese sido lo que fue, me refiero a la creación y posterior desarrollo de la Sección Etnohistoria perteneciente al Instituto de Ciencias Antropológicas de la Facultad de Filosofía y Letras de la Universidad de Buenos Aires. En 1985 Ana María creó una Sección que le permitiría desarrollar su vida académica como ella deseaba, donde pudiera realizar sus estudios conforme a sus intereses personales, y desde la que pudiera pedir subsidios y por tanto formar becarios y tesistas ${ }^{1}$. Tal vez ella no lo tuviera totalmente en claro al momento de colocar la piedra basal, pero así resultó. Ana María alimentó a la Sección y luego se realimentó de ella, la dirigió hasta el año 2014 (López Pascual 2011). Esta es parte de su historia.

\section{Ana María y su encuentro con la Etnohistoria}

En el período del gobierno dictatorial que va desde 1976 a 1983, las Ciencias Antropológicas al igual que la mayoría de las Ciencias Sociales en Argentina, sufrieron embates impensados. En el primer caso, fueron cerradas las Carreras en las Universidades Nacionales de Rosario y Mar del Plata, mientras que en la de Buenos Aires se intentó que la Licenciatura dejase de ser tal para convertirse en una especialización de posgrado para historiadores. La resistencia del Colegio de Graduados en Antropología, acompañado por la gran mayoría de la comunidad científica, logró frenar la propuesta.

La vuelta a la democracia implicó la reorganización de la Antropología en la Universidad de Buenos Aires y la misma afectó tanto a la Licenciatura como también a su Instituto de Investigación. La persona elegida para la reorganización de este último fue Ana María Lorandi, alguien que, paradójicamente, para ese momento no estaba ligada a la Universidad de Buenos Aires. La tarea recayó en Ana María, tal vez como ella misma recuerda, por no estar estrictamente ligada "ni a los arqueólogos ni con los antropólogos

\footnotetext{
* Universidad de Buenos Aires, Instituto de Ciencias Antropológicas, Sección Etnohistoria. Instituto Nacional de Antropología y Pensamiento latinoamericano, Argentina. Correo electrónico: cezanolli@ hotmail.com
} 
sociales" y, como ella dijera, por "venir de afuera", es decir, no de la propia Universidad de Buenos Aires sino de la Universidad Nacional de La Plata.

La trayectoria académica de Ana María se inicia en 1960, momento que obtuvo el título de Profesora en Historia y siete años después, a los 31 años, el de Doctora, ambos por la Universidad Nacional del Litoral. El doctorado le valió como antecedente importante para ingresar tempranamente en la Carrera de Investigador Científico del Concejo Nacional de Investigaciones Científicas y Tecnológicas (CONICET). A pesar de sus títulos, Ana María se fue especializando en Arqueología de la mano de Alberto Rex González, uno de los principales exponentes de la disciplina en el país. Por aquel entonces, la Arqueología en Argentina comenzaba a hacerse más científica considerando que en la década de 1940 "había empezado a darse una renovación teórico-metodológica en la arqueología sudamericana, vinculada a las excavaciones norteamericanas en el Perú"2 (Zanolli, et al. 2016: 185).

Hacia fines de la década de 1960 Lorandi siguió a Alberto Rex González a la Universidad Nacional de La Plata donde obtuvo el cargo de Profesora en la materia Arqueología Americana II (Grupos Agroalfareros). En aquella Universidad, Ana María tomó contacto con Augusto Cardich quien desde 1961 estaba a cargo de la cátedra de Arqueología Americana I (Culturas Precerámicas), y quien tuvo una gran influencia en sus trabajos posteriores.

En 1966, en la ciudad de Mar del Plata, se realizó el XXXVII Congreso Internacional de Americanistas, evento donde Ana María conoció al arqueólogo chileno Lautaro Núñez, quien luego la invitaría al Primer Congreso del Hombre Andino. Un año más tarde Lorandi asistió al Congreso Internacional de Arte Rupestre realizado en Huánuco (Perú), donde tomó contacto por primera vez con John Murra, antropólogo y referente internacional de la Etnohistoria andina.

En 1969 Lorandi inició, por motivos personales, varios viajes a Francia, adonde en 1977 se radicaría por tres años. Durante su estadía en Francia afianzó sus lazos con Murra, participó en los cursos que ofrecían Nathan Wachtel y su equipo en el École des Hautes Études en Sciences Sociales, y también dictó otros propios. Ya familiarizada con los temas etnohistóricos, en 1973 Lorandi asistió al Primer Congreso del Hombre Andino realizado por la Universidad de Chile, donde participó del Simposio "Verticalidad y colonización andina pre-europea" con la ponencia "El área andina y sus vecinos" (Lorandi, 1973). La Etnohistoria decididamente había alterado los intereses académicos de Ana María.

Lorandi no se encontraba cómoda en la Universidad Nacional de La Plata, y el ofrecimiento para hacerse cargo de la dirección del Instituto de Ciencias Antropológicas de la Universidad de Buenos Aires la llenó de nuevas expectativas. Ya al frente del Instituto, Ana María lo dividió en seis Secciones: Folklore, Biológica, Etnología y Arqueología, todas líneas tradicionales dentro de la Antropología que se venía desarrollando en el país. La quinta fue la Sección de Etnohistoria, algo que para ese momento muy pocos sabían qué era, y la última, la de Antropología Social, rama de la disciplina que nunca había podido despuntar en el país por motivos políticos.

\section{Los comienzos de la Sección Etnohistoria}

Ya como Directora de la Sección, Ana María evaluó que sería imposible lograr parte de sus expectativas si no obtenía subsidios para la investigación, y así fue que el mismo año de creación de la Sección presentó un proyecto al Consejo Nacional de Investigaciones Científicas y Técnicas (CONICET), tal vez el primero que haya llevado la palabra "Etnohistoria" en el título: "La etnohistoria, estado actual de la disciplina en relación con la situación prehispánica y colonial de los Andes Centrales y su proyección en el estudio del antiguo Tucumán". El proyecto englobaba dos subproyectos, uno con claro énfasis en la Etnohistoria y otro en la Arqueología. El mismo estaba integrado por representantes de tres disciplinas: Arqueología, Antropología e Historia. Como era de esperarse, los evaluadores del CONICET cuestionaron la amplitud del proyecto aduciendo que incluía objetivos de "naturaleza diversa". Inmediatamente Ana María elaboró un informe en respuesta, en el mismo manifestaba que "Todo está fuertemente ligado y no se pueden entender los procesos de cambio de la sociedad nativa sin comprender la naturaleza y los intereses del grupo dominante" (Zanolli et al. 2010: 49) y agregaba que dichos temas interdependientes serían abordados por distintos grupos de trabajo que intercambiaban periódicamente información del avance de sus investigaciones (Carullo y Vaccarezza, 1997). 
Esta respuesta, que en el 2017 puede parecer un hecho anecdótico, no lo era hace treinta años. Con ese proyecto, pero también con esa respuesta, Ana María institucionalizaba en la Universidad de Buenos Aires un nuevo campo de estudio, el que entre otros, trataba un viejo sujeto de estudio de la Antropología: el indígena. Luego entre 1988 y 1993, y con Ana María como directora de los proyectos, la Sección Etnohistoria obtuvo tres subsidios más con dos claras consecuencias que me gustaría señalar: En primer lugar, ya se comenzaba a observar que un modelo nacido en principio para los Andes Centrales fue reelaborado para el Tucumán colonial. En segundo lugar, la incorporación de becarios, tesistas y alumnos, los que no solo ampliaban los temas de estudio de las Sección, sino que también interpelaban sus conocimientos. Transcurridos unos cinco años de la creación de la Sección, y entrada la década de 1990, algunos hechos merecen destacarse:

a) En primer lugar y retomando lo que dijimos unos párrafos antes, se había avanzado de manera prácticamente definitiva en el conocimiento de la estructura social del Tucumán colonial, echando las bases para futuras investigaciones que se realizaran ya desde la propia Sección como así también desde otras universidades o centros de estudio tanto de Buenos Aires como del interior del país.

b) En 1990 se incorporó a la Sección la Dra. Lidia Nacuzzi, si se quiere inaugurando una nueva área de estudio, la de Pampa-Patagonia. La incorporación de la Dra. Nacuzzi -y su equipo de trabajo- amplió las fronteras de estudio al interior de la Sección, incorporando nuevas geografías y por qué no, nuevas problemáticas.

c) En 1991 se publicó el primer volumen de Memoria Americana, su creadora fue la doctora Ana María Lorandi, quien permaneció como directora de la Revista hasta 2007. La Revista publica artículos de investigación en el campo de la etnohistoria, la antropología histórica y la historia colonial de América Latina, con el objetivo de difundir ampliamente los avances en la producción de conocimiento de esas áreas disciplinares. La publicación continúa saliendo hasta la actualidad.

d) Finalizaba la década de 1980 y Ana María intuyó la necesidad de realizar un encuentro de etnohistoriadores, en otras palabras, de institucionalizar un campo de estudio que había ganado un espacio impensado tanto en la zona andina como en el resto del continente. El resultado fue la realización en 1989 del Primer Congreso Internacional de Etnohistoria, una instancia de encuentro que si se quiere a lo largo de los años funcionó como un marco de encuentro, de intercambio, pero por sobre todas las cosas como una vidriera de lo que sucedía al interior de los equipos de investigación que a lo largo del tiempo se fueron consolidando en los diferentes países. Los CIE se comenzaron a desarrollar de manera bianual, luego se espaciaron, pero lo cierto es que nunca se interrumpieron de manera definitiva, estando actualmente a las vísperas de la realización del décimo encuentro en la ciudad de Quito, Ecuador.

Aquel proceso de consolidación de la Sección se mantuvo por lo menos hasta el 2000 con otros hitos dignos de señalar:

a) En 1997 se publicó el libro El Tucumán Colonial y Charcas, un proyecto pensado en 1995 con la idea de compilar en una sola publicación la producción más relevante de la Sección hasta ese año.

b) En 1998 se dictó por primera vez, en el marco de la Licenciatura en Ciencias Antropológicas, el Seminario Anual de Investigación que en aquel momento llevó el nombre de Teoría y Metodología de la Antropología Histórica. El Seminario estuvo a cargo de la Dra. Lorandi y de investigadores formados en la Sección (Soprano, 2010).

c) En 1998 se realizó un Seminario interno que tuvo dos propósitos: "realizar una revisión de obras claves de ambas disciplinas [Antropología e Historia] e incitar a una discusión, también teórica y metodológica, sobre la construcción del conocimiento que cada uno de nosotros había emprendido" (Lorandi y Wilde 2000: 7). Los resultados del Seminario fueron publicados en el número 9 del año 2000 de Memoria Americana.

La ampliación del número de integrantes de la Sección mediante nuevos becarios y tesistas, de la mano también de ciertos cambios que venían produciéndose en la academia en cuanto a los 
tiempos para licenciarse y doctorarse se refiere, traería consecuencias y por supuesto nuevos desafíos al interior de la misma. Entre las más destacadas es posible señalar la ampliación de los temas/problemas de investigación, y también de los actores involucrados, alejándose de manera paulatina de los pueblos indígenas como actores excluyentes de las investigaciones. Los cambios en la definición del objeto de estudio estuvieron ligados a cierta actualización teórica, fruto de nuevas formas de pensar que se estaban dando tanto en la Historia -por ejemplo, con el desarrollo de la microhistoria italiana-, en la Antropología a partir de los trabajos de Sahlins y Jean y John Comaroff, y en las Ciencias Sociales en general con la perspectiva renovadora de autores como Giddens y Bourdieu, entre otros (Zanolli et al. 2010: 74).

Junto con la consolidación de estos cambios surgió al interior de la Sección la denominación de Antropología Histórica, primero como sinónimo de Etnohistoria y perfilándose luego como algo parcialmente diferente y que a la vez designaba de una mejor manera la producción realizada en la misma.

\section{Desde su consolidación hasta la actualidad}

Luego de casi diez años de existencia, a comienzos de 1994, la Sección Etnohistoria contaba con aproximadamente veinte personas entre la totalidad de sus integrantes, también a partir de esa fecha y hasta la actualidad, los subsidios radicados en la Universidad de Buenos Aires llevan por título "Cambio y continuidad en la sociedad indígena e hispano-criolla, siglos XV-XIX", hecho que evidencia la ampliación de actores, temporalidades, integrantes y temas de investigación. El UBACyT FI 090, 1994-1997, incluyó dos particularidades respecto de los proyectos anteriores: en primer lugar, hubo una ampliación geográfica, ya que además de la tradicional andina meridional se incluía a la región de Pampa-Patagonia. En segundo lugar, por primera vez desde la creación de la Sección la sociedad hispano-criolla ocupó un objetivo principal dentro de los proyectos de investigación. La inclusión de la sociedad hispanocriolla encuentra justificación de inclusión en el propio proyecto donde dice: a) que "el equipo está integrado por un número considerable de miembros", y b) que la gran mayoría de los que venían trabajando comenzaron a analizar "la larga duración y la posibilidad de una aproximación al presente" (UBACyT FI 090. 1994-1997). Con el tiempo, los proyectos de Pampa-Patagonia continuaron con una dinámica propia.

Ya avanzado el siglo XXI, esta "forma de investigar", que de alguna manera había inaugurado o mejor dicho institucionalizado Ana María, se había desarrollado a lo largo del país generando una gran cantidad de bibliografía. Esa línea en el UBACyT F 091. 2008-2011 era reconocida como de Antropología Histórica:

En los últimos años y en diversos centros universitarios del país, se ha desarrollado un gran número de investigaciones relativas a las regiones del NOA, Cuyo y Litoral y sus relaciones con los países limítrofes desde una perspectiva que aborda temáticas del pasado colonial y republicano a partir de marcos teóricos de la antropología histórica y de una cuidadosa hermenéutica del discurso (UBACyT F 091, 2008-2011).

Y en él, también se definían algunos de sus aspectos fundamentales: 1) interpretación de las fuentes bajo estricto control del valor y límites de los datos; 2) Relación dialógica entre distintos actores y grupos sociales, atendiendo a las adaptaciones, resistencias y negociaciones, tanto en aspectos concretos de la vida cotidiana, la economía y las prácticas políticas como de la manipulación de significados identitarios y simbólicos. El nuevo proyecto daba cuenta entonces que la Antropología Histórica había desembarcado tímidamente en la Sección a fines de la década de 1990 y que esta, ya a principios del nuevo siglo, se había destacado como una nueva forma de investigar. El abandono del término Etnohistoria para caracterizar a las investigaciones desarrolladas en la Sección no fue el simple resultado de una elección consciente que, a la par que buscaba reforzar su filiación con la Antropología, intentaba quedar habilitada para desarrollar nuevas temáticas de investigación, al margen de aquellas asociadas al estudio de la sociedad indígena en el periodo colonial temprano.

El último proyecto que armó y dirigió Ana María fue el del trienio 2014-2017 en este, y debido a la amplísima diversidad de temas que se investigaban en la Sección, ya se avisaba que era "necesario dividir estos conocimientos de acuerdo con los dos grandes bloques: Andino (Argentina y Bolivia) y 
Tierras Bajas (Argentina, Paraguay, sur de Brasil y Uruguay)" (UBACyT 200201130100238BA), estableciendo un objetivo general amplísimo para ambas y luego específicos conforme cada una de las áreas. No cabe duda que esta nueva forma de presentar los proyectos de "Cambio y Continuidad" estaban mostrando dos caras de la misma moneda, en primer lugar, que la "población" de la Sección se había duplicado respecto de hace veinte años, contando ya con varios nuevos doctores. En segundo lugar, las dificultades que implicaría, a partir del 2017, realizar un único proyecto que englobe la pluralidad de temas que unos años antes habían comenzado a consolidarse en la Sección.

\section{Luego de Ana María}

En el 2014 Ana María dejó la dirección de la Sección y también, aunque no lo vislumbráramos en aquel momento, la dirección de los futuros proyectos de investigación.

Dejaba atrás una obra en ese momento difícil de dimensionar. El primer lugar dejaba armada y funcionando a pleno una Sección equiparable en su aspecto académico a los mejores Institutos de la Facultad de Filosofía y Letras de la Universidad de Buenos Aires. En ella, prácticamente desde el mismo momento de su creación, no hubo un año en que no se contase con un subsidio para la investigación, hecho que posibilitó que, a lo largo de treinta años, se hayan licenciado y doctorado una cantidad muy grande de personas. Fue en ese contexto y en esa coyuntura que Ana María tuvo la flexibilidad e inteligencia para favorecer y alimentar la aparición de esos nuevos temas. Hoy es a partir de ellos que la Sección cuenta con la posibilidad de continuar ampliando sus bases.

Ana María definió la historia de trabajo en la Sección como una "gran experiencia compartida", en el sentido de una retroalimentación mutua y permanente. Tempranamente Ana María sorprendió con sus trabajos que analizaban al Tucumán colonial como una doble frontera, para adentrarse luego de lleno -y junto con su equipo- en los procesos históricos del NOA y del sur de Bolivia. Al momento de su fallecimiento, y casi como una consecuencia lógica, analizaba cómo esos procesos abrieron las puertas a la causa revolucionaria y a las guerras de independencia. Paralelamente el equipo de PampaPatagonia avanzaba en los procesos económicos, políticos y culturales que se generaron a partir de la conquista y colonización de los territorios de los actuales estados de Argentina y Chile. A esos dos temas generales y característicos de la Sección, en la actualidad debemos sumarles aquellos que trabajan las Tierras Bajas, los realizados desde la Antropología Histórica de la Religión, y los que analizan los procesos de conformación de un campo disciplinar como la Etnohsitoria, la transmisión de saberes, y la íntima relación entre Ciencias Sociales y Política. Como dijimos al comienzo mismo de esta reseña, no sabemos si Ana María tuvo una real dimensión de lo que estaba inaugurando allá por 1985, lo que es cierto es que esa acción, derivada en una multiplicidad de trabajos y estudios, ha producido un significativo y original aporte para el desarrollo de las Ciencias Sociales tanto nacionales como latinoamericanas.

\section{Referencias Citadas}

Carullo, J. C. y L. Vaccarezza

1997 El incentivo a la investigación universitaria como instrumento de promoción y gestión de la I+D. Redes 4 [en línea].

Lorandi, A. M.

1973 "El área andina y sus vecinos. I Congreso del Hombre Andino". Boletín Especial Resúmenes: s/p. Universidad de Chile, Antofagasta.

Lorandi, A. y G. Wilde

2000 "Desafío a la isocronía del péndulo. Acerca de la teoría y de la práctica de la Antropología histórica". Memoria Americana. Cuadernos de Etnohistoria 9: 37-78, Facultad de Filosofía y Letras. U.B.A. Buenos Aires.

López Pascual, J.

2011 "Intelectuales: cartas, redes e instituciones. El archivo epistolar del Colegio Libre de Estudios Superiores de Bahía
Blanca en el cruce de la Historia y la Antropología (19411952)". Revista de Estudios Marítimos y Sociales 4: 107-17. Soprano, G.

2010 "La enseñanza de la arqueología en la Facultad de Ciencias Naturales y Museo de la Universidad Nacional de La Plata. Un análisis sobre el liderazgo académico de Alberto Rex González y Eduardo Mario Cigliano (1958-1977)". Revista del Museo de Antropología 3: 171-186.

Steward, J. (ed.)

1946 Handbook of the South American Indians. The Andean civilizations, Vol. 2, Smithsoninan Institution, Washington DC.

Zanolli, C.; A. Ramos, D. Estruch y C. Costilla

2010 Historia, representaciones y prácticas de la Etnohistoria en la Universidad de Buenos Aires. Una aproximación 
antropológica a un campo de confluencia disciplinar. Antropofagia, Buenos Aires.

Zanolli, C.; A. Ramos y C. Chiappe

2016 "Itinerarios académicos de Ana María Lorandi”. En: Disciplinas sin fronteras. Homenaje a Ana María Lorandi, editado por: Boixadós, R y C. Bunster, pp. 183-217. Ed. Facultad de Filosofía y Letras (UBA), Buenos Aires.

\section{Documentos Citados}

1994-1997. UBACyT. F 090: Cambio y continuidad en la sociedad indígena e hispano-criolla, Siglos XV-XIX.

2008-2011. UBACyT. F 091. Cambios y continuidades en la sociedad indígena e hispano-criolla.

2014-2017. UBACyT. 20020130100238BA. Cambios y continuidades en la sociedad indígena e hispano-criolla.

\section{Notas}

1 Al final de su vida Ana María había formado una gran cantidad de becarios y tesistas, entre ellos: Verónica Williams, Lidia Nacuzzi, Mercedes del Río, Cristina López de Albornoz, Carlos Zanolli, Roxana Boixadós, Mercedes Avellaneda, Guillermo Wilde, Pablo Ortemberg, Lorena Rodríguez, entre tantos otros.
2 Los trabajos surgidos en esta época fueron publicados en el Handbook of the South American Indians editado por Julian Steward (1946), siendo particularmente importante para el volumen dedicado a los países centro-sur andinos. 